\title{
Refractive Index and Spectral Reflection in Three Leaf Categories of Strawberry (Fragaria $x$ ananassa Duch.)
}

\author{
P.D. Abeytilakarathna ${ }^{*}$, R.M. Fonseka ${ }^{1}$, J.P. Eeswara ${ }^{1}$ and H.M.D.K. Herath ${ }^{2}$ \\ Postgraduate Institute of Agriculture \\ University of Peradeniya \\ Sri Lanka
}

\begin{abstract}
A study was carried out to examine the refractive index $(R I)$ and red $(R)$, green $(G)$ and blue $(B)$ colour spectral reflection of strawberry (Fragaria $x$ ananassa Duch.) leaves. Digital photographs and their respective refractive indices of thirty trifoliate leaves from three leaf categories, i.e. most recently mature trifoliate leaves (MRTL), old trifoliate leaves (OTL) and leaf spot disease-infected trifoliate leaves (LSTL) of strawberry $c v$. $C h a n d l e r$ were analysed. The highest $R I$ was found in $O T L$. The spectral reflection of $R, G, B$ $(R+G+B)$ and spectral indices of $B / R,(R-B) /(R+B)$ and $B /(R+G+B)$ were not significantly different $(p<0.05)$ among the three leaf categories. Higher values were reported for the indices $G / R$ and $R /(R+G+B)$, and a low value for $G /(R+G+B)$ in $L S T L$ compared to other two leaf categories. The normalized difference index of $[(G-R) /(G+R)] 2$ was higher in $M R T L$ than OTL. There was no any significant relationship among RI and spectral reflection of strawberry leaves.
\end{abstract}

Keywords: Leaf spectral reflection, plant quality, refractive index, $R G B$ colour intensity, strawberry

\section{INTRODUCTION}

Farmers need straight forward, reliable, low cost tool to measure the quality of crops. Refraction index (RI) is normally used to assess fruit ripeness, but Huang et al, (2007) proposed that it can be used to assess quality parameters of vegetable. The refractive index of leaf sap is more important as it is a direct measurement of how the plant performs. Measuring sugar level in plant directly corresponds to how much sugar production has taken place in the plant (Biobased, 2013). In addition, RI can be used to help monitor underlying problems in the soil in which the produce is grown (Pein, 2001). RI of leaf sap can aid variety selection, harvest scheduling, and other aspects of crop production including irrigation, fertility, and postharvest management (Bumgarner \& Kleinhenz, 2012). A plant with low RI makes an easy target for insects that sense the plant's ill health and will hone in for an easy feed. Healthy plant have higher RI, indicates superior resistance to pests and diseases, which ultimately means less time and expenses are needed be spent on pest control measures (Pein, 2001).

Refractometric analysis using juice is laborious and involves destructive handling of a considerable amount of leaves from a single plant making it difficult to be practiced under

\footnotetext{
Department of Crop Science, Faculty of Agriculture, University of Peradeniya, Sri Lanka

Agricultural Research Station, Department of Agriculture, Rahangala, Boralanda, Sri Lanka

Corresponding author: abeytilaka@yahoo.com
} 
local farming conditions. Therefore, a non-destructive simple method for determining the RI of leaf is vital for small scale strawberry farmers in Sri Lanka.

Elmary et al. (2007) used hyper spectral imaging technology for measuring fruit maturity, firmness and soluble solid content of strawberry. The total intensity values of Red $(R)$, green (G) and blue (B) colour by adding together $(\mathrm{R}+\mathrm{G}+\mathrm{B})$ and the $[(\mathrm{G}+\mathrm{B}-\mathrm{R}) /(\mathrm{R}+\mathrm{B}+\mathrm{G})]^{2}$ index were strongly correlated $\left(\mathrm{R}^{2}=0.95\right.$ and 0.89 , respectively) with the TSS of strawberry fruits (Abeytilakarathna et al., 2013). In the present study it was hypothesized that the spectral reflection and refractive indices would vary with different types of strawberry leaves and hence, an attempt was made to calculate RI and spectral reflection of strawberry leaves.

\section{MATERIALS AND METHODS}

\section{Agronomic practices}

Strawberry (Fragaria $x$ ananassa Duch.) cv. Chandler was grown in an open field at the Agricultural Research Station of the Department of Agriculture (DOA) at Rahangala, Boralanda, Sri Lanka in the Maha season (September 2012 - February 2013) and Yala season (March-August 2013). Inorganic fertilizers were applied at the rate of $80 \mathrm{~kg}$ of urea, $160 \mathrm{~kg}$ of triple super phosphate (TSP) and $40 \mathrm{~kg}$ of muriate of potash (MOP) per ha as the basal dressing. Also compost was applied at the rate of 10 t/ha three days before planting. Strawberry nursery plants were planted at a spacing of $40 \mathrm{~cm} \times 30 \mathrm{~cm}$. Application of fertilizer as top dressing and other cultural practices were carried out as per the recommendations made by the Department of Agriculture, Sri Lanka (DOA, 2007).

\section{Measurement of leaf spectral reflectance}

Three categories of strawberry leaves namely, recently matured trifoliate leaves (MRTLs), old trifoliate leaves (OTLs) and leaf spot disease-infected (caused by the fungus Mycosphaerella fragariae ) trifoliate leaves (LSTLs) were collected.

Digital photographs of each leaf at the size of two mega pixels were taken (Fujifilm finepix AV100 camera) using flash, before testing the total soluble solids (TSS). The average mean pixel intensities of Red, Green and Blue (RGB) colour of the images were analyzed using the Image J 1.46r software of the National Institute of Health, USA. Thirty trifoliate leaves from each category were used to measure the spectral reflectance and TSS content of leaves.

\section{Measurement of the Refractive Index of leaves}

Strawberry leaf extracts were obtained after grinding the leaves by using mortar and pestle. The Refractive Index of leaf extracts was measured using a hand-held ATAGO® master-50H refractometer having built-in automatic temperature compensation.

\section{Statistical analysis and calculation of spectral reflection intensities}

AssiStat version 7.6 beta (2012) software was used to perform the statistical analysis of the data. The average RGB indices were calculated using the pixel intensity values of the images. The indices of $R /(R+G+B), G /(R+G+B), B /(R+G+B), G / R, G / B, B / R,(R-B) /(R+B)$, $(\mathrm{G}-\mathrm{B}) /(\mathrm{G}+\mathrm{B}),[(\mathrm{G}-\mathrm{R}) /(\mathrm{G}+\mathrm{R})]^{2}$ and $[(\mathrm{R}+\mathrm{B}-\mathrm{G}) /(\mathrm{R}+\mathrm{B}+\mathrm{G})]^{2}$, where $\mathrm{R}=$ average red colour intensity, $\mathrm{G}=$ average green colour intensity, $\mathrm{B}=$ average blue colour intensity and $\mathrm{R}+\mathrm{G}+\mathrm{B}=$ 
average red, green and blue colour intensities were calculated. Regression analysis was done among RI and spectral reflection indices.

\section{RESULTS AND DISCUSSION}

A significant difference $(\mathrm{p}<0.01)$ of RI was observed among the strawberry leaves tested. The highest RI was observed in OTLs (4.83 percent ${ }^{\circ}$ Brix) while MRTLs and LSTLs showed lower RI (2.83 and 3.58 percent ${ }^{\circ}$ Brix respectively). There was no significant difference $(\mathrm{p}>0.05)$ of $\mathrm{R}, \mathrm{G}, \mathrm{B}$ and $(\mathrm{R}+\mathrm{G}+\mathrm{B})$ values with three different leaf categories (Table 1).

Table 1. The average refraction index and average colour spectral reflection intensities of three different types of strawberry leaves.

\begin{tabular}{lcccc}
\hline Leaf Category & $\begin{array}{l}\text { Refractive index } \\
\left({ }^{\circ} \text { Brix }\right)^{* * *}\end{array}$ & $\begin{array}{l}\text { Red colour } \\
\text { intensity }\end{array}$ & $\begin{array}{l}\text { Green colour } \\
\text { intensity }\end{array}$ & $\begin{array}{l}\text { Blue colour } \\
\text { intensity }^{\text {ns }}\end{array}$ \\
\hline MRTLs* & $2.83^{\mathrm{c}}$ & 53.40 & 84.55 & 28.74 \\
OTLs & $4.83^{\mathrm{a}}$ & 80.15 & 108.96 & 50.13 \\
LSTLs & $3.58^{\mathrm{b}}$ & 76.56 & 80.66 & 45.86 \\
\hline CV \% & 18.38 & 26.85 & 26.29 & 44.17 \\
\hline
\end{tabular}

MRTLs: recently-matured trifoliate leaves, OTLs: old trifoliate leaves, LSTLs: Leaf spot disease-infected trifoliate leaves

${ }^{\mathrm{ns}}$ Non-significant at $\mathrm{p}=0.05$

** Significant at $\mathrm{p}=0.01$

Within each column, the means followed by the same letter are not significantly different by the Duncan's Multiple Range test $(\mathrm{p}=0.01)$

Even though, there was no significant difference ( $p>0.05$ ) observed among the R,G,B reflections with the three types of leaf categories, some indices that were derived from $\mathrm{R}, \mathrm{G}$, and $B$ colour intensities i.e. $\mathrm{G} / \mathrm{R}, \mathrm{G} / \mathrm{B}$ (Table 3), $\mathrm{R} /(\mathrm{R}+\mathrm{G}+\mathrm{B}), \mathrm{G} /(\mathrm{R}+\mathrm{G}+\mathrm{B})$ (Table 2), [(G$\mathrm{B}) /(\mathrm{G}+\mathrm{B})]^{2}$ and $[(\mathrm{RB}-\mathrm{G}) /(\mathrm{R}+\mathrm{G}+\mathrm{B})]^{2}($ Table 4$)$ were significantly different $(\mathrm{p}<0.05)$ while $B / R, B /(R+G+B)$ and $(R-B) /(R+B)$ were not significantly different $(p>0.05)$ among the three leaf categories. The lowest values for the indices $G / R, G / B$ and $G /(R+G+B)(1.02,1.83$ and 0.39 , respectively) and the highest value of $\mathrm{R} /(\mathrm{R}+\mathrm{G}+\mathrm{B})(0.39)$ were recorded in LSTLs. Ellis et al., (2006) reported that when chlorophyll breakdowns faster than it is synthesized, the process allows the anthocyanin-like colour pigments to be masked. The molecules reflecting red wavelengths such as anthocyanins are water-soluble pigments that occur in the cell sap creating the red, pink and purple hues. The formation of anthocyanin requires bright light, a diminishing water supply and the accumulation of sugars trapped in the leaf. Therefore, $\mathrm{R} /(\mathrm{R}+\mathrm{G}+\mathrm{B})$ values increased with the increment of red colour reflection while $\mathrm{G} /(\mathrm{R}+\mathrm{G}+\mathrm{B})$ values reduced as green colour reflection decreased in LSTLs. In addition, G/R values were also significantly lower $(\mathrm{p}<0.05)$ in the LSTLs.

Table 2. The average colour reflection ratio of three different categories of strawberry leaves.

\begin{tabular}{lcccc}
\hline \multicolumn{1}{c}{ Leaf category } & $(\mathrm{R}+\mathrm{G}+\mathrm{B})^{\mathrm{ns}}$ & $\mathrm{R} /(\mathrm{R}+\mathrm{G}+\mathrm{B})^{*}$ & $\mathrm{G} /(\mathrm{R}+\mathrm{G}+\mathrm{B})^{* *}$ & $\mathrm{~B} /(\mathrm{R}+\mathrm{B}+\mathrm{G})^{\mathrm{ns}}$ \\
\hline MRTLs & 166.68 & $0.32^{\mathrm{b}}$ & $0.51^{\mathrm{a}}$ & 0.17 \\
OTLs & 239.24 & $0.33^{\mathrm{b}}$ & $0.46^{\mathrm{a}}$ & 0.21 \\
LSTLs & 203.08 & $0.39^{\mathrm{a}}$ & $0.39^{\mathrm{b}}$ & 0.23 \\
\hline CV \% & 27.95 & 10.77 & 10.28 & 19.67 \\
\hline
\end{tabular}

MRTLs: recently-matured trifoliate leaves, OTLs: old trifoliate leaves, LSTLs: Leaf spot disease-infected trifoliate leaves

*Significant $\mathrm{p}=0.05, * *$ Significant at $\mathrm{p}=0.01$

ns Non-significant at $\mathrm{p}=0.05$

Within each column, the means followed by the same letter are not significantly different by the Duncan's Multiple Range test. 
Table 3. Red, green and blue colour Spectral reflection indices of three types of strawberry leaves.

\begin{tabular}{lccc}
\hline Leaf Categories & G/R** & G/B* & B/R ${ }^{\text {ns }}$ \\
\hline MRTLs & $1.59^{\mathrm{a}}$ & $3.12^{\mathrm{a}}$ & 0.53 \\
OTLs & $1.38^{\mathrm{a}}$ & $2.28^{\mathrm{ab}}$ & 0.63 \\
LSTLs & $1.02^{\mathrm{b}}$ & $1.83^{\mathrm{b}}$ & 0.57 \\
\hline CV \% & 14.89 & 29.52 & 25.57 \\
\hline
\end{tabular}

MRTLs: recently-matured trifoliate leaves, OTLs: old trifoliate leaves, LSTLs: Leaf spot disease-infected trifoliate leaves

$*$ Significant at $\mathrm{p}=0.05, * *$ Significant at $\mathrm{p}=0.01$

ns - Non-significant at $\mathrm{p}=0.05$

Within each column, means followed by the same letter are not significantly different by the Duncan's Multiple

Range Test at $\mathrm{p}=0.01$

As for the normalized difference spectral reflection indices, the highest values of [(G$\mathrm{R}) /(\mathrm{G}+\mathrm{R})]^{2}$ index for MRTLs was 0.051 while the lowest values for OTLs and LSTLs were 0.026 and 0.019 , respectively. The highest $[(R+B-G) /(R+G+B)]^{2}$ index was seen in LSTLs (0.06) while the lowest values were found in MRTLs and OTLs (0.02 and 0.009, respectively; Table 4).

Table 4. The normalized difference spectral reflection indices of three different types of strawberry leaves.

\begin{tabular}{lcccc}
\hline Leaf categories & $(\mathrm{R}-\mathrm{B}) /(\mathrm{R}+\mathrm{B})^{\mathrm{ns}}$ & $(\mathrm{G}-\mathrm{B}) /(\mathrm{G}+\mathrm{B})^{*}$ & {$[(\mathrm{G}-\mathrm{R}) /(\mathrm{G}+\mathrm{R})]^{2} * *$} & {$[(\mathrm{R}+\mathrm{B}-\mathrm{G}) /(\mathrm{R}+\mathrm{B}+\mathrm{G})]^{2} *$} \\
\hline MRTLs & 0.31 & $0.50^{\mathrm{a}}$ & $0.051^{\mathrm{a}}$ & $0.002^{\mathrm{b}}$ \\
OTLs & 0.23 & $0.38^{\mathrm{ab}}$ & $0.026^{\mathrm{b}}$ & $0.009^{\mathrm{b}}$ \\
LSTLs & 0.28 & $0.27^{\mathrm{b}}$ & $0.019^{\mathrm{b}}$ & $0.06^{\mathrm{a}}$ \\
\hline CV \% & 42.55 & 31.40 & 46.16 & 145.09 \\
\hline
\end{tabular}

MRTLs: recently-matured trifoliate leaves, OTLs: old trifoliate leaves, LSTLs: Leaf spot disease-infected trifoliate leaves

$*$ Significant at $\mathrm{p}=0.05, * *$ Significant at $\mathrm{p}=0.01$

ns - Non-significant at $\mathrm{p}=0.05$

Within each column, means followed by the same letter are not significantly different by the Duncan/s multiple Range Test at $\mathrm{p}=0.01$

Even though, the spectral reflection indices of $G / R, G / B, R /(R+G+B), G /(R+G+B),(G-$ $\mathrm{B}) /(\mathrm{G}+\mathrm{B}),[(\mathrm{G}-\mathrm{R}) /(\mathrm{G}+\mathrm{R})]^{2}$ and.$[(\mathrm{R}+\mathrm{B}-\mathrm{G}) /(\mathrm{R}+\mathrm{G}+\mathrm{B})]^{2}$ showed a significant difference among different leaf categories comparable to RI, the linear regression analysis did not show a significant relationship between RI and the spectral reflection indices (Table 5).

Table 5. Regression analysis of refractive indices and spectral reflection indices of strawberry leaves.

\begin{tabular}{|c|c|}
\hline Regression analysis & R-square \\
\hline RI vs. G/R & $0.004^{\mathrm{ns}}$ \\
\hline RI vs. G/B & $0.080^{\mathrm{ns}}$ \\
\hline RI vs. $R /(R+G+B)$ & $0.018^{\mathrm{ns}}$ \\
\hline RI vs. $G /(R+G+B)$ & $0.011^{\mathrm{ns}}$ \\
\hline RI vs. (G-B)/(G+B) & $0.043^{\mathrm{ns}}$ \\
\hline RI vs. $[(\mathrm{G}-\mathrm{R}) /(\mathrm{G}+\mathrm{R})]^{2}$ & $0.277^{\mathrm{ns}}$ \\
\hline RI vs. $[(R+B-G) /(R+G+B)]^{2}$ & $0.298^{\mathrm{ns}}$ \\
\hline
\end{tabular}

${ }^{n s}$ Non-significant at $\mathrm{p}=0.05$ 


\section{CONCLUSION}

The refractive index was higher in OTLs than MRTLs. But there was no any significant relationship with RI and the red, green and blue spectral reflection indices due to leaf colour changes occurred by leaf spot disease. The reflections of red, blue and green colour along were also not suitable to estimate RI as surrounding light condition may interfere with the light reflection. Consequently, these indices are not suitable to measure the leaf RI since they specially do not identify the disease affected leaves. Therefore, further studies are proposed for the indirect estimation of leaf refractive index of strawberry leaves by using infrared light reflection.

\section{REFERENCES}

Abeytilakarathna, P.D., Fonseka, R.M., Eeswara, J.P. and Wijethunga, K.G.N.A.B. (2013). Relationship between total solid content and red, green and blue colour intensity of strawberry (Fragaria x ananassa Duch.) fruits. J. Agric. Sci. 8(2), 82-90.

Biobased (2013). Why is Brix measurement important? [Online]. [Accessed on 04.07.2013]. Available at http://www.biobased.us/tech1.html

Bumgarner, N.R. and Kleinhenz, M.D. (2012). Using ${ }^{0}$ Brix as an indicator of vegetable quality. Fact sheet; agriculture and natural resources. Department of horticulture and crop science, The Ohio State University, Ohio Agricultural Research and Development Centre, USA.

DOA (2007). Fertilizer Recommendation for Horticultural Crops - Strawberry. Department of Agriculture, Peradeniya, Sri Lanka. p 86.

Ellis, M.A., Funt, R.C., Wright, S., Demchak, K., Wahle, E., Doohan, D., Welty, C., Williams, R.N. and Brown, M. (Eds.) ( 2006). Integrated management of strawberry diseases. Midwest strawberry production guide, the Ohio State University, USA. pp 37-38.

Elmary, G., Wang, N., ElSayed, A. and Nagadi, M. (2007). Hyper spectral imaging for nondestructive determination of some quality attributes for strawberry. J. of Food Engineering 81(1), 98-107. [online] [ Accessed on 04.07.2013]. Available at http://www.nutrientdense.info/brix/WhatIsBrix.htm

Huang, L., Wang, C. and Bomford, M. (2007). Effect of plant source, age and foliar molasses application on Brix reading of kale extract. American society for Horticultural Science Annual conference, 16-20 July, Scottsdale, AZ.

Pein, D.V. (2001). Meters for modern farmers; obtaining optimum prices by looking after your soil. [online]. [Accessed on 04.07.2013]. Available at http://www.themeterman.com.au/interview.php 